\title{
Recent advances in observing mesoscale ocean dynamics with satellite altimetry
}

\author{
Rosemary Morrow $^{\mathrm{a}, *}$, Pierre-Yves Le Traon ${ }^{\mathrm{b}}$

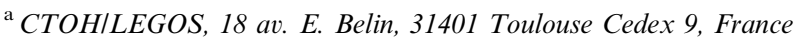 \\ ${ }^{\mathrm{b}}$ IFREMER and Mercator-Ocean, 8-10 rue Hermès, 31520 Ramonville-St-Agne, France
}

Available online 12 October 2011

\begin{abstract}
The paper provides a review of recent results on mesoscale ocean dynamics derived from satellite altimetry. Since 1992, we have had an unprecedented 18 year high-resolution monitoring of the ocean mesoscale field. Altimetry is often used in mesoscale studies in synergy with other remote sensing techniques and in situ data. This global, high-resolution data set has allowed oceanographers to quantify the previously unknown seasonal and interannual variations in eddy kinetic energy and eddy heat and salt transports, and investigate their causes. Eddy tracking techniques have allowed us to monitor their propagation pathways, to bring to light the meridional divergence of cyclones and anticyclones, and to question the role of Rossby waves versus non-linear eddies in the mid to high latitude bands. Altimetry has also revealed the presence of zonal fronts and jets everywhere in the ocean, and brought to light how mesoscale eddies can impact back onto the atmospheric circulation. Finally, altimetry, in synergy with other observations and high-resolution numerical models, has helped reveal the complexity of the sub-mesoscale features, associated with stirring and mixing around the mesoscale eddies, of great importance for the vertical exchange of oceanic tracers. Altimetry has revealed the complexity of the mesoscale system... the scientific community is now working to understand the interplay between these mesoscale eddies, the ocean interior and its impact on the overlying atmosphere.
\end{abstract}

(C) 2011 COSPAR. Published by Elsevier Ltd. All rights reserved.

Keywords: Satellite altimetry; Mesoscale eddies; Ocean circulation

\section{Introduction}

The ocean, like the atmosphere, is a fundamentally turbulent system. When we observe animations of the ocean's sea level changes, what is most striking is that all of the world's oceans are full of small-scale eddies and meanders, and at all latitude bands. The circulation is indeed dominated by mesoscale variability, due to ocean eddies or isolated vortices, meandering currents or fronts, squirts and filaments. The mesoscale variability generally refers to ocean signals with space scales of $50-500 \mathrm{~km}$ and time scales of 10-100 days.

In the ocean, the energy of these mesoscale processes generally exceeds that of the mean flow by an order of magni-

\footnotetext{
* Corresponding author.

E-mail address: rosemary.morrow@legos.obs-mip.fr (R. Morrow).
}

tude or more. Most of the eddy energy is generated by instabilities of the mean flow (Stammer and Wunsch, 1999), but fluctuating winds can also provide a direct forcing mechanism, which is particularly evident in low eddy energy regions (Frankignoul and Müller, 1979). Eddies can feed energy and momentum back into the mean flow and help drive the deep ocean circulation (Morrow et al., 1994; Lozier, 1997). They also transport heat, salt, carbon, and nutrients as they propagate in the ocean, and play a significant role in the global budgets of these tracers. Eddies are the principal mechanism for the poleward transport of heat across strong zonal currents, such as the Antarctic Circumpolar Current (ACC) (Karsten and Marshall, 2002; Jayne and Marotzke, 2002). Mesoscale processes also have a strong impact on the ecosystem, and on most operational oceanography applications (e.g. marine safety, pollution monitoring, offshore industry, fisheries, etc.). 
Over the last two decades, satellite altimetry has provided a global, high-resolution, regular monitoring of sea level and ocean circulation variations. The early satellite altimetry missions such as SEASAT (1978) and GEOSAT (1986-1989) provided our first global coverage of the ocean mesoscale sea level variations. Geosat data were extensively used for studying the ocean mesoscale dynamics. For the first time the eddy space and time scales were characterised (Le Traon, 1991) and their regional variations investigated with respect to turbulence theory. The position and strength of meandering jets were monitored in the Gulf Stream, the Kuroshio and the Antarctic Circumpolar Current (ACC) (Kelly and Gille, 1990; Qiu, 1992; Gille, 1994), and eddy-mean interactions were also investigated (Tai and White, 1990; Morrow et al., 1994). A review of the early mesoscale studies with satellite altimetry is given by Le Traon and Morrow (2001) and Fu et al. (2010).

We will review here some of the recent advances which have been made in studying mesoscale ocean dynamics with satellite altimetry. What has changed since 1992, is the presence of at least two altimeter missions in orbit at the same time (and up to 5 in 2002!) providing precise measurements and the complementary sampling that is needed for ocean mesoscale variability monitoring (see Le Traon and Morrow, 2001; Fu et al., 2010). This multi-mission period has been underpinned by the very precise TOPEX/POSEIDON (T/P) mission which was launched in 1992 on a 10day repeat, and followed by Jason-1, launched in 2001 and the Ocean Surface Topography Mission OSTM/ Jason-2 in 2008. At the same time, ERS-1 (1991-1995), ERS-2 (1995-2005) and ENVISAT (2002 ->) were in orbit providing higher-latitude and finer spatial coverage on a 35 -day repeat. GFO launched in 2000 on a 17-day repeat provided additional complementary altimetric coverage (Fig. 1). The minimum requirement for a good representation of the ocean mesoscale variability is that at least two altimeter missions are in orbit, including one very precise long-term altimeter system (Koblinsky et al., 1992). For near-real time operational studies, a minimum of 3 or 4 altimeters are required (Le Traon and Dibarboure, 2002).

In the following sections we will present some of the exciting advances in the field of mesoscale ocean dynamics, derived from this multi-mission period. Section 1 deals with the mapping of multi-mission data onto a regular grid for mesoscale studies. We will then review various scientific applications, including investigating the seasonal and interannual variations in eddy kinetic energy (EKE) (Section 2), the observed propagation characteristics of mesoscale eddies and Rossby waves (Section 3), the role of eddies in transporting heat, salt and other tracers in the ocean (Section 4), studies on meandering jets and fronts (Section 5), the interaction between mesoscale eddies and jets and the atmospheric circulation (Section 6), and finally the importance and difficulty in observing sub-mesoscale processes (Section 7). The conclusions and perspectives are given in Section 8.

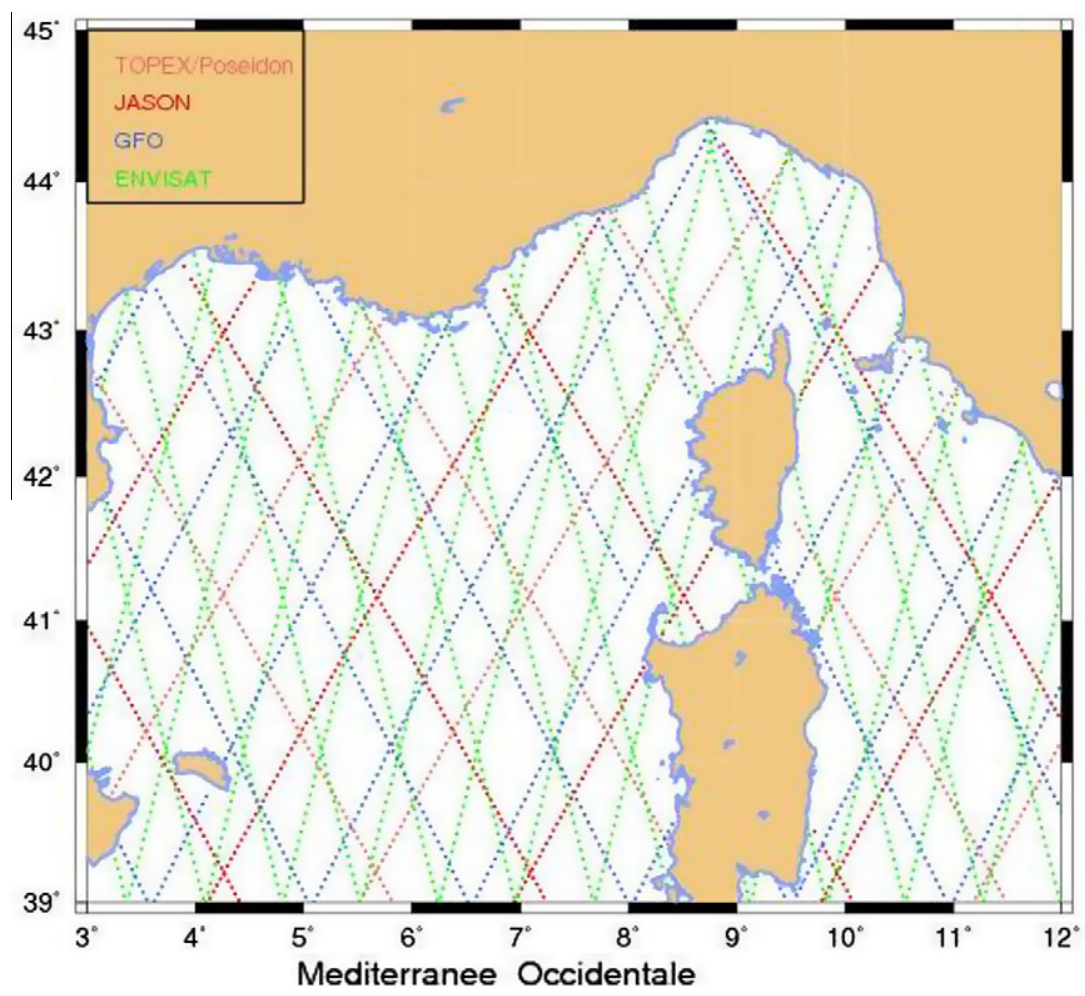

Fig. 1. 35 day coverage of altimeter missions in the NW Mediterranean Sea in January 2005. Topex-Poseidon (light red), Jason (dark red), ENVISAT (Green), GFO (blue). (For interpretation of the references to colour in this figure legend, the reader is referred to the web version of this article.) 


\section{Multi-mission mapping capabilities}

All of the altimeter missions regularly sample sea level at $10-20 \mathrm{~Hz}$ (or $1 / 10-1 / 20 \mathrm{~s}$ ) along their groundtracks, although most mesoscale ocean studies use the mean value every $1 \mathrm{~s}(7 \mathrm{~km})$. However in any given region over a 10 day period, the groundtrack patterns from different missions lay out an irregular space-time coverage (see Fig. 1). Merging the different altimetric missions is a delicate task, since each mission has different error budgets and orbit differences which lead to large-scale biases and trends which need to be corrected. Dibarboure et al. (2011) describe the sub-optimal interpolation technique which is currently used by the SSALTO/DUACS project to construct global gridded data sets from multi-mission altimeter data. Before mapping, a crossover analysis minimises the errors between groundtracks, including a correction for the large-scale orbit errors. All of the available altimetric data is then mapped onto a regular $1 / 3^{\circ}$ Mercator grid every 7-10 days, which allows for an easy analysis of the multi-mission data, and a good representation of the mesoscale dynamics.

Le Traon and Dibarboure (2002) provided a summary of the mapping capabilities of the T/P + ERS (Jason$1+$ ENVISAT) configuration, using realistic simulations from the eddy-resolving $1 / 10^{\circ}$ Los Alamos POP Model (Smith et al., 2000). Modeled $1 / 10^{\circ}$ resolution sea level anomalies were subsampled along altimeter tracks, with a random noise added. The SSALTO/DUACS sub-optimal interpolation technique was then applied to the subsampled data in order to reconstruct the 2D sea level anomaly signal. The reconstructed sea level based on the altimetry sampling was then compared to the original full-resolution model fields. The difference in sea level allows an estimation of the sea level and velocity mapping errors. They found that with two altimeters in the T/P-ERS configuration, sea level can be mapped with an error which is less than $10 \%$ of the signal variance while the velocity can be mapped with an error of $20-40 \%$ of the signal variance (depending on latitude) (see Fig. 2). A large part of the mapping error is due to high-frequency, high wavenumber signals. Errors are reduced when 10-day averages are made, but also when a high-frequency, low-wavenumber dynamic atmospheric correction is applied, such as MOG2D (Carrere and Lyard, 2003).

Although the 2-altimeter "Reference" merged data provide a very good representation of the mesoscale variability, the missing $10 \%$ of the variance can be quite important especially for correctly determining the velocity field in coastal and mesoscale situations (see discussions in Greenslade et al. (1997)). Since September 2002, Jason-1 and Topex/Poseidon have been orbiting in the so-called "tandem mission": T/ $\mathrm{P}$ was maneuvered westward to fly halfway between the Jason groundtrack, and the two satellites continued in this tandem orbit until T/P expired in September 2005. The objectives of the tandem mission were to provide improved spatial resolution of the surface topography for ocean meso- scale studies and coastal tides, and also to improve the surface geostrophic currents. By comparing results from the tandem mission with independent ERS-2 data, Le Traon and Dibarboure (2004) showed that, in regions with large mesoscale variability, the sea level and velocity can be mapped respectively with an error of about $6 \%$ and 20 $30 \%$ of the signal variance. Stammer and Theiss (2004) calculated alongtrack geostrophic velocities from the tandem mission, and compared the velocities to in situ observations from Acoustic Doppler current profiles along a groundtrack near Bermuda. They found the tandem mission geostrophic velocity variances to be around $25 \%$ lower than the in situ current variance, which include both geostrophic and ageostrophic components. These direct tandem mission velocity results were similar to those of Le Traon and Dibarboure (2002) who calculated their velocities from the mapped T/ $\mathrm{P}+$ ERS data. The tandem mission provides, however, better results when compared with $\mathrm{T} / \mathrm{P}+$ ERS mapping capabilities. To further improve the ocean velocity field would require altimetric observations at around $10 \mathrm{~km}$ spatial resolution, as proposed by the future wide-swath altimetric technology (see Section 7).

From mid-September 2002 to the demise of GFO in late 2008, we have had an exceptional sampling of the ocean with at least four altimeter missions flying simultaneously [Jason-1, ERS-2/ENVISAT, T/P interleaved with Jason-1 and Geosat Follow-On (GFO)]. These merged data sets can greatly improve the estimation of surface mesoscale circulation, and a number of regional, multi-mission gridded products have been developed at higher $1 / 8^{\circ}$ resolution, in the Mediterranean Sea (Pujol and Larnicol, 2005; Pascual et al., 2005), the Black Sea and in near-real time for the Mozambique channel. ${ }^{1}$ In the Mediterranean Sea, mean EKE was computed from the different altimeter configurations and the combination of Jason-1 + ERS-2 failed to reproduce some intense signals (Pascual et al., 2005). When $\mathrm{T} / \mathrm{P}$ was added, these features are recovered and the EKE shows no significant discontinuities due to sampling effects. On average, the merged Jason-1 + ERS$2+\mathrm{T} / \mathrm{P}+\mathrm{GFO}$ maps yield EKE levels $15 \%$ higher than the two-satellite configuration of Jason-1 + ERS-2. The consistency between altimetry and sea surface temperature, drifting buoys and tide gauges, was also significantly improved when four satellites are merged compared to the results derived from the two-satellite configuration.

In the northeast Atlantic (Dussurget et al., 2011) have analysed the alongtrack eddy scales and amplitudes using reprocessed altimeter data specifically adapted to improving coastal dynamics (Roblou et al., 2010). They find that close to the generation sites near bathymetric gradients, there is a large number of small-scale smallamplitude eddies, with space scales around $50-70 \mathrm{~km}$, whereas further offshore, the scales and amplitudes

\footnotetext{
${ }^{1}$ http://www.aviso.oceanobs.com/en/data/products:sea-surface-heightproducts/regional/index.html.
} 

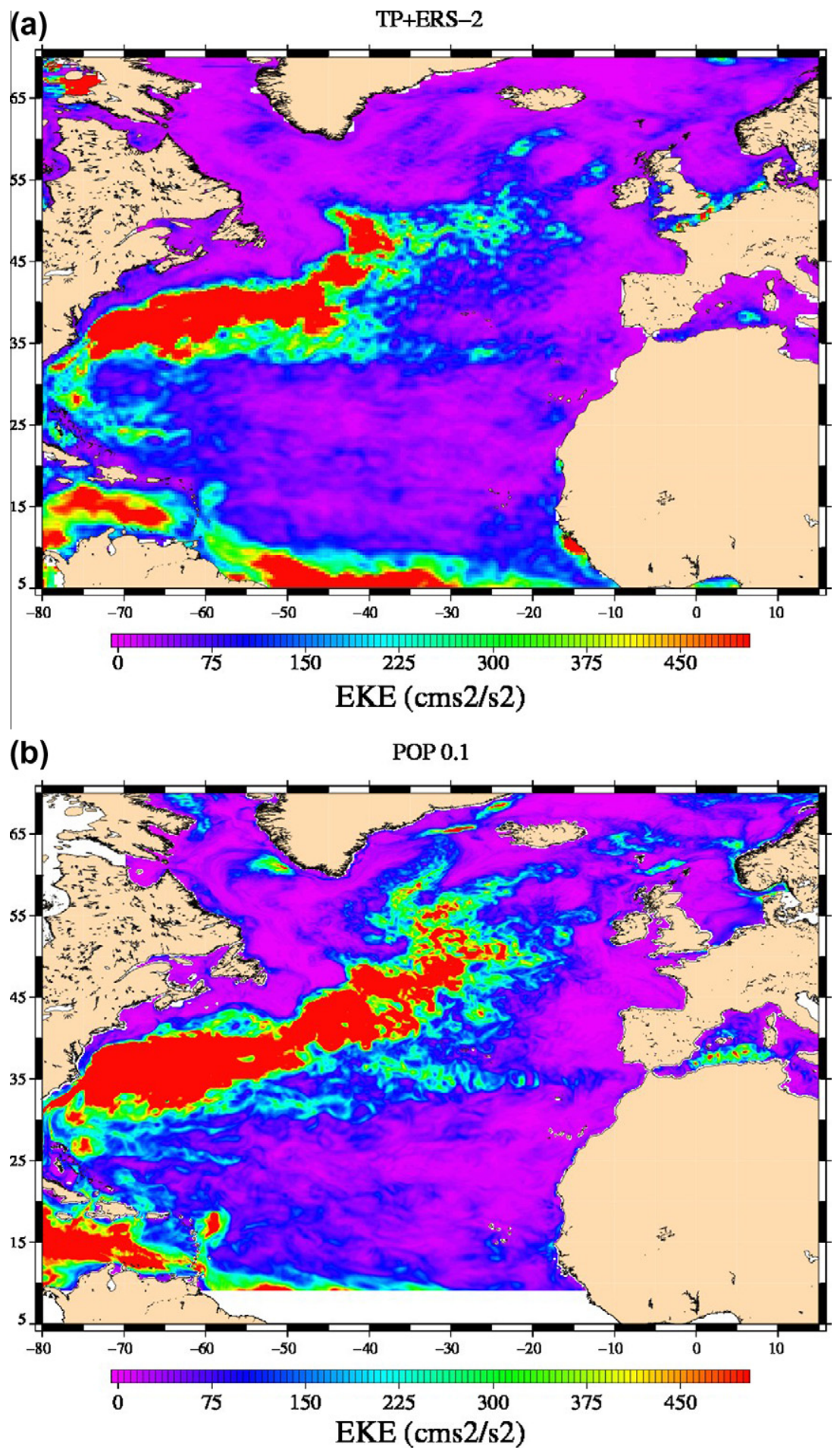

Fig. 2. Comparison of EKE levels in the North Atlantic ocean calculated from model sea level data subsampled along T/P + ERS groundtracks (left) and from the full $1 / 10^{\circ}$ resolution POP model (right).

increase, with space scales increasing to $120-150 \mathrm{~km}$. Only the offshore eddies are correctly represented in the present generation of global DUACS AVISO altimetry maps. This change of scale and amplitude of the observed eddies moving offshore is consistent with 2D geostrophic turbulence, and has also been simulated using numerical models (McWilliams, 1984). Regional maps of multi-mission data have also been constructed which maintain the smallerscale nearshore eddy features, with better agreement with independent data (Dussurget et al., 2011).

All of these studies demonstrated that at least three, but preferably four, altimeter missions are needed for monitoring the coastal and mesoscale circulation. Similar conclusions were reached in a study performed for the glo- 
bal ocean (Pascual et al., 2006). In areas of intense variability, the rms differences between a classical configuration of two altimeters and the scenario merging four missions were shown to reach up to $10 \mathrm{~cm}$ and $400 \mathrm{~cm}^{2} / \mathrm{s}^{2}$ in sea level and EKE, respectively.

\section{Seasonal and interannual variations in eddy kinetic energy}

A decade-long time series with regular spatial sampling allows us, for the first time, to consider the seasonal and interannual variations in EKE, and the dynamics responsible for these changes. Altimetric EKE variations have been studied in the Mediterranean Sea (Pujol and Larnicol, 2005) and in the Bay of Biscay (Caballero et al., 2007), and the regional variations have been investigated in relation to different forcing mechanisms (wind stress, varying coastal currents, etc). Brachet et al. (2004) also analyzed the temporal evolution of the monthly EKE over an 8-year period (from December 1992 to December 2000) and investigated the relationship with the wind stress in several regions. Their results follow previous studies which link seasonal EKE variations at high latitudes to seasonal wind stress variations, although other forcing mechanisms may also be important as discussed by Eden and Böning (2002). Clear EKE interannual variability was revealed. They hypothesized that a contraction of the subpolar and subtropical gyres due to the North Atlantic Oscillation (NAO) could explain a reduction of the eddy activity in the North Atlantic Current, in the Newfoundland basin and in the Azores Current. Penduff et al. (2004) also found that strong NAO events after 1994 were followed by gyrescale EKE fluctuations with a 4-12-month lag, suggesting complex and nonlinear adjustment processes.

In the Southern Ocean south of Tasmania, Morrow et al. (2002) have shown how interannual variations in EKE can be linked to interannual changes in the position and strength of the Subantarctic Front. Over the entire Southern Ocean, the EKE variations also show a lagged response to the principal climate mode forcing from the Southern Annular Mode (Meredith and Hogg (2006), modified by ENSO (Morrow et al., 2010). The mechanisms which generate the observed 2 year lag in eddy energy have also been explored with model simulations (Hogg and Blundell, 2006).

Merged T/P and ERS data sets have also allowed a better investigation of EKE seasonal variations (see le Traon and Morrow (2001) for a review). The North Pacific Subtropical Counter Current (NPSTCC) around $20^{\circ} \mathrm{N}$ is shown to have a well-defined seasonal modulation in its EKE field (Qiu, 1999). Using a 21/2 layer model to represent the vertically-sheared NPSTCC-NEC system, they found that the observed seasonal modulation reflected the intensity of baroclinic instability of the sheared current system. In the South Pacific, Qiu and Chen (2004) detected high EKE bands with well-defined annual cycles along the eastward-flowing surface currents of both the South Tropical Countercurrent (STCC) between $21^{\circ}-29^{\circ} \mathrm{S}$ and the South
Equatorial Countercurrent (SECC) centered near $9^{\circ} \mathrm{S}$. Once again, the seasonal variation in the intensity of baroclinic instability was found to be responsible for the seasonal modulation of the STCC's EKE field around $25^{\circ} \mathrm{S}$ (Fig. 3). However, the seasonal modulation of the SECC's EKE field around $10^{\circ} \mathrm{S}$ was mainly generated by the seasonal variation in the intensity of barotropic instability associated with seasonal changes in the strong horizontal shear of the SECC-SEC system.

\section{Eddy propagation characteristics}

Although the ocean is a turbulent system, long-term altimetric monitoring of the global ocean mesoscale signal has shown that the instabilities propagate in an organized way. The fundamental property of ocean mesoscale instabilities is that they are large enough, and of long duration, to be in quasi-geostrophic balance and to be influenced by the rotation of the Earth. Movies of ocean sea level anomalies show a continual movement of mesoscale eddies towards the west, at all latitude bands.

A major discovery from the long time series of multimission altimetry data was that the sea level anomalies propagated westward with a wave speed up to twice as fast as that predicted from linear Rossby wave theory (Chelton and Schlax, 1996). This observational discovery led to host of revised theories on Rossby wave propagation, which took into account the vertical shear in the background flow, bathymetric effects, etc. (for a review see Fu and Chelton, 2001). Although the difference between these revised theories and the observed propagation speeds has been reduced, the observed speeds remain faster than theory predicts.

Most of the difference occurs at mid to high latitude, and Chelton et al. (2007) raise the question of whether the observed propagation is due to Rossby waves at these latitudes, or whether the instabilities are associated with isolated non-linear vorticies. Non-linear vorticies also propagate westward (Cushman-Roisin et al., 1990) but interact differently with the background flow. Unlike Rossby waves, they also transport heat, salt and tracers in their core waters, which can have consequences for the midlatitude tracer budgets (see Section 4). In addition, many studies using in situ observations to determine the vertical structure of mid-latitude sea level anomalies analyse a vertical "eddy" structure (Carton and Chao, 1999; de Ruitjer et al., 1999; Morrow et al., 2003) although Roemmich and Gilson (2001) suggest that their subsurface temperature anomalies in the North Pacific mid-latitudes appear "wavelike".

A number of studies have tracked the propagation pathways of individual eddies at mid to high latitude using the mapped multi-mission altimetric sea level anomalies. Different automatic eddy tracking techniques have been developed and tested on altimetry data, based on the Okubu-Weiss parameter (e.g. Isern-Fontanet et al., 2003), the skewness of the relative vorticity (Niiler et al., 2003); 

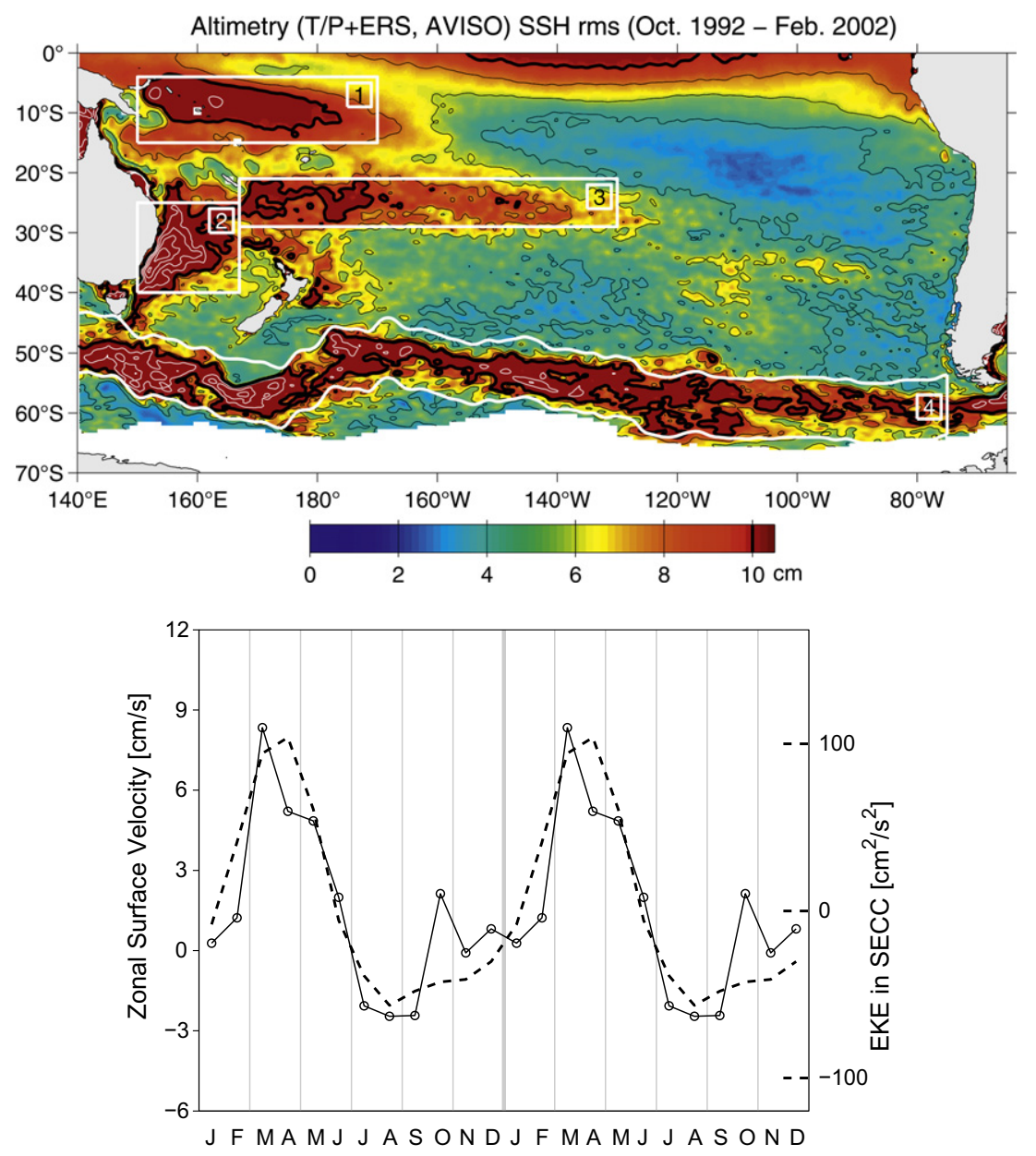

Fig. 3. (a) Map of the rms sea surface height variability from T/P + ERS data in the South Pacific Ocean. Box 1 highlights the SECC variability, Box 3 the STCC variability. (b) Zonal velocity shear between 0 and $600 \mathrm{~m}$ for the STCC-SEC from monthly climatological data (solid line) compared to altimeter EKE (dashed line) (after Qiu and Chen, 2004 @ American Meteorological Society).

criteria based on sea level (Fang and Morrow, 2003; Chaigneau and Pizarro, 2005; Chelton et al., 2011), wavelet decomposition of the SLA (e.g. Lilly et al., 2003), or a geometric criteria using the winding angle approach (e.g. Souza et al., 2011). Depending on the technique used, there can be differences in the number of eddies detected, their duration and their propagation velocities. For example, in the Agulhas retroflection region, numerous studies have used a combination of altimetric sea level maps and concurrent in situ observations to track warm-core Agulhas rings into the south Atlantic (see de Ruitjer et al., 1999 for a review). The number of Agulhas warm-core rings generated varies from year to year, and their pathways can vary in response to interannual changes in the South Atlantic gyre strength. However, the different automatic eddy tracking techniques can produce slightly different results, even though they all use the same gridded altimetric SLA fields (Souza et al., 2011).

Altimetric maps have revealed that eddy corridors exist in a large number of regions. de Ruitjer et al (2004) analysed eddies and dipoles South of Madagascar. They observed the regular formation of dipoles around south
Madagascar, where the East Madagascar Current (EMC) separates from the shelf. Two periods of enhanced dipole formation coincided with the negative phases of the Indian Ocean Dipole and the El Niño cycles, suggesting a connection between these tropical climate modes and the dipole train formation. A very regular train of dipoles started in December 1999 and continued through 2000. They stayed remarkably coherent and triggered an unusually early retroflection of the Agulhas Current in late 2000. Thus, interannual variability originating in the equatorial climate modes of the Indian Ocean can impact on the variability of the Agulhas retroflection and associated ring shedding.

In the South Indian Ocean, Fang and Morrow (2003) analysed the pathways of anticyclonic warm-core eddies from 1995 to 2000 . They found long-lived warm-core eddies that could be tracked for periods longer than 6 months and over distances greater than $1500 \mathrm{~km}$. The number of eddies varied interannually with the ENSO cycle ... more long-lived warm-core eddies were generated during La Nina conditions when the upper ocean thermal content along the West Australian coast was more important. Eddies were steered by bathymetry into three main corri- 
dors. Eddy radius and propagation speeds decreased over the first 3 months, after which there was a slower evolution of the eddy characteristics over time. In the Canary Basin, a similar corridor of eddies is generated by the perturbation of the Canary Current by the Canary Islands (Sangrà et al., 2009).

These different studies highlighted that although eddies propagated westward, the warm and cold-core eddies tracked over long periods often showed distinct meridional propagation. In three regional studies, Morrow et al. (2004a) found divergent pathways of cyclonic and anticyclonic ocean eddies (Fig. 4). Away from bathymetry or strong background mean flow, warm-core eddies tend to propagate westward and equatorward and cold-core eddies

(a)

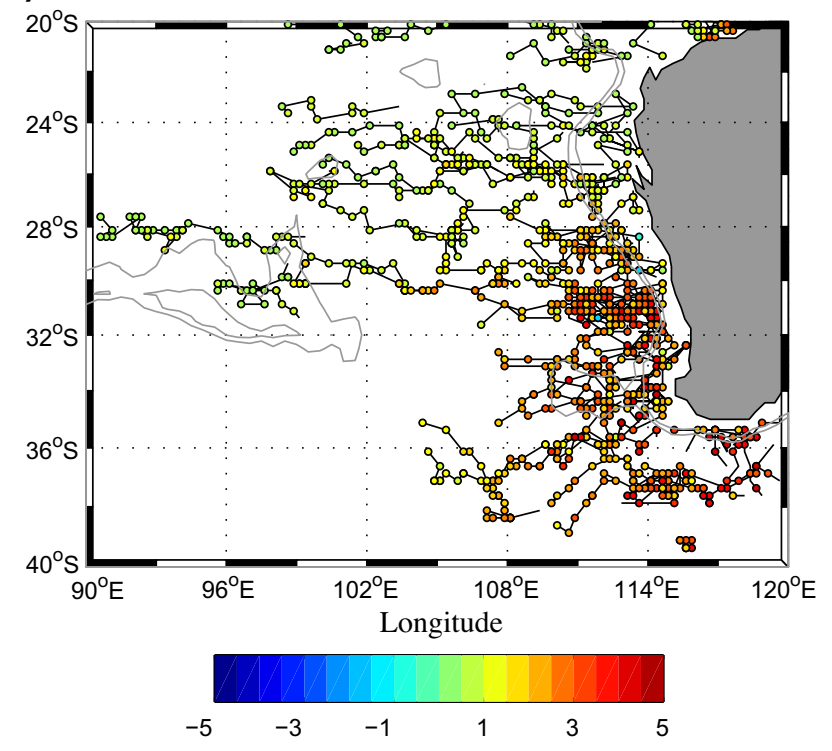

(b)

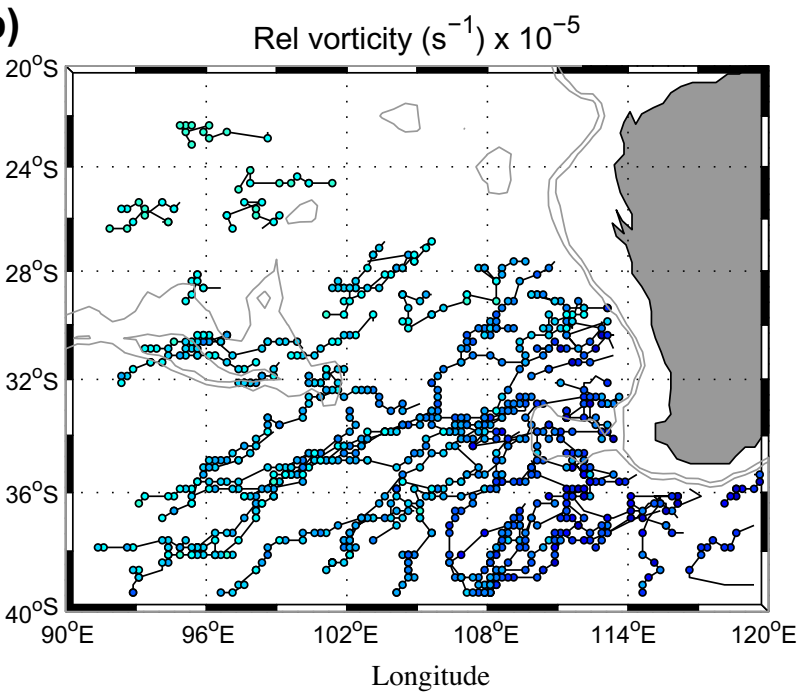

Fig. 4. Propagation pathways and relative vorticity for long-lived (a) anticyclonic and (b) cyclonic eddies detected in the SE Indian Ocean from 5 years of mapped TP + ERS data. In this region $84 \%$ of cyclones propagate poleward and $74 \%$ of anti-cyclones propagate equatorward (after Morrow et al., 2004a, (C) American Geophysical Union). tend to propagate westward and poleward. This implies a net equatorward heat flux from these long-lived eddies. The clearest example is the South Indian Ocean where the background mean flow is weak and the eddy signal is large. The tendency of large cyclonic eddies to move poleward and anticyclones to move equatorward probably results from the $\beta$-effect and the conservation of potential vorticity. This behaviour has been noted in many regions, in the Agulhas (e.g. Boebel et al., 2003), in the southeast Pacific (Chaigneau and Pizarro, 2005) and has been confirmed by a global analysis by Chelton et al. (2011) (Fig. 5).

Finally, the basic "rules" of westward or meridional propagation can be overturned in regions of strong mean currents or strong bathymetric steering. Numerous studies based on altimetric observations show eddies advected by the mean circulation in the NW Pacific (Isoguchi and Kawamura, 2003); in the ACC (Hughes et al., 1998; Fu, 2009), and in the North Atlantic (Brachet et al., 2004).

\section{Eddy heat and salt transports}

Eddy heat and salt transports can be estimated from a combination of multi-mission altimetry and in situ data. Different techniques have been developed. Stammer (1998) calculated global mean estimates of eddy diffusivities and eddy heat and salt fluxes using altimetry for the velocity field and a statistical parameterization of the down-gradient heat or salt flux derived from annual climatological temperature and salinity fields. The results show the first global, high-resolution estimates of eddy heat and salt fluxes. These results need to be updated now that we have a longer time-series and better in situ data coverage to resolve the meridional gradients.

An alternative technique is to estimate the available heat and salt content for individual eddies using high resolution hydrographic sections from CTDs or gliders, or Argo profiles which traverse the eddy. A typical eddy vertical structure is thus established. Altimetry is then used to determine population statistics, such as the number of such eddies generated per year, their decay time, and their propagation direction. Annual mean heat and salt transports can then be estimated. This type of technique has been successfully applied in the Agulhas region by numerous authors (e.g. see the review article by de Ruitjer et al. (1999)). Van Ballegooyen et al. (1994) found that the amount of heat and salt entering the south Atlantic due to the Agulhas warm-core eddies, was $0.045 \mathrm{PW}$ and $3 \times 10^{5} \mathrm{~kg} \mathrm{~s}^{-1}$, respectively.

A similar technique was used to estimate the annual eddy heat and salt fluxes carried by warm-core Leeuwin Current eddies into the southern Indian Ocean. Morrow et al. (2003) found that long-lived anti-cyclones contributed $0.013 \mathrm{PW}$ of heat and $5 \times 10^{5} \mathrm{kgs}^{-1}$ of salt, moving westnorthwest. The magnitude of these southeast Indian Ocean eddy heat fluxes is $3-10 \%$ of the net heat loss to the atmosphere in the subtropical gyre. In the Southern Ocean south of Tasmania, Morrow et al. (2004b) showed that cyclonic 

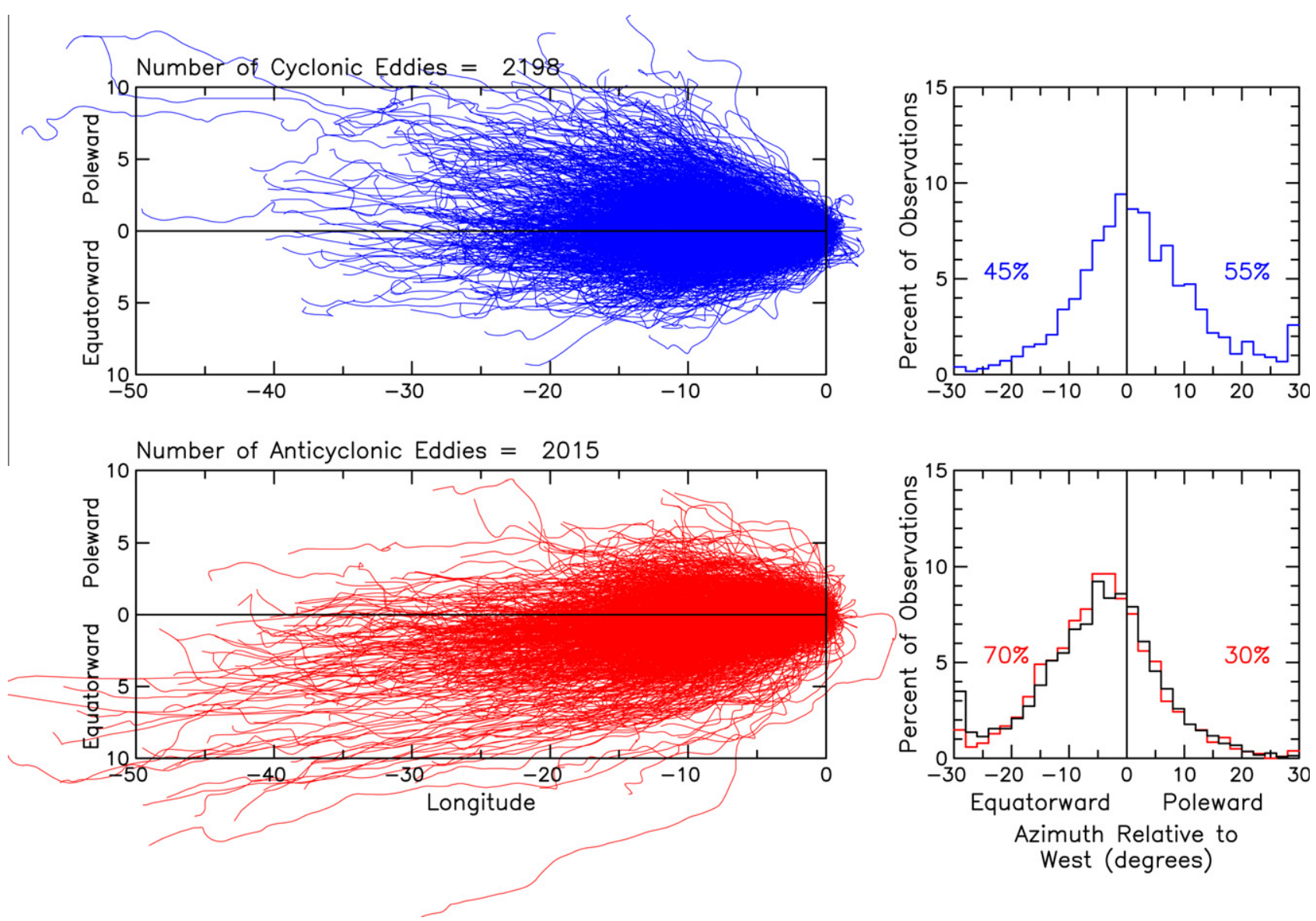

Fig. 5. Global analysis of the meridional propagation of long-lived (a) cyclonic and (b) anti-cyclonic eddies from 10 years of mapped TP + ERS data. In the global analysis, 55\% of cyclones propagate poleward and 70\% of anti-cyclones propagate equatorward (after Chelton et al., 2011, (C) Elsevier B.V.).

eddies were instrumental in transporting cool, fresh water in the upper $1000 \mathrm{~m}$ into the Subantarctic Zone where mode waters form. The amount of eddy heat and salt transported was estimated to be of the same order as that carried by the northward Ekman transport in the surface layer.

In the North Pacific, 8 years of high resolution XBT transects and $\mathrm{T} / \mathrm{P}$ altimetric data were used to estimate the eddy heat transport in the North Pacific (Roemmich and Gilson (2001). The in situ observations are combined to determine composite warm and cold-core eddy structures (Fig. 6), which slant westward with decreasing depth. This tilt produces a depth-varying velocity/temperature correlation and hence a vertical-meridional overturning circulation. On average, $3.9 \mathrm{~Sv}$ of thermocline waters are carried equatorward by the eddy field over the basin, balanced by the northward transport of surface waters. Interannual eddy variability was found to be the dominant mechanism for interannual changes in the equatorward transport of thermocline water, which can impact directly on the tropical coupled dynamics.

Argo data have led to improved space-time sampling of the ocean vertical structure in the upper $2000 \mathrm{~m}$. Qiu and Chen (2005) showed an interesting estimation of basin-scale heat transport induced by mesoscale oceanic eddies in the North Pacific by combining high resolution altimeter and sea surface temperature maps with Argo float temperature and salinity data. Time-varying heat budgets for the surface mixed-layer have also been established in different oceanic regions (Chaigneau et al., 2004; Sallée et al., 2006). More recently, combinations of altimetry with gliders have highlighted the fine-scale structure of the mesoscale processes. In the Labrador Sea, altimetry and gliders are being used to track eddies spawned from the west Greenland boundary current (Hátún et al., 2007). These eddies transport low salinity upper waters and warm, saline Irminger waters at depth. Individual eddies can contribute to the rapid restratification of the Labrador Sea interior after periods of deep winter convection, and may help explain why the deep convection region is so small, compared to the larger scale atmospheric forcing.

\section{Meandering jets and fronts}

In two-dimensional turbulence on a $\beta$-plane, a longterm free evolution of an eddy field should result in the formation of alternating zonal jets. Using $\mathrm{T} / \mathrm{P}$ and ERS merged data sets, Maximenko et al. (2008) have shown that alternating jet-like structures are seen in geostrophic velocity anomalies (Fig. 7) and, also geostrophic vorticity, in 

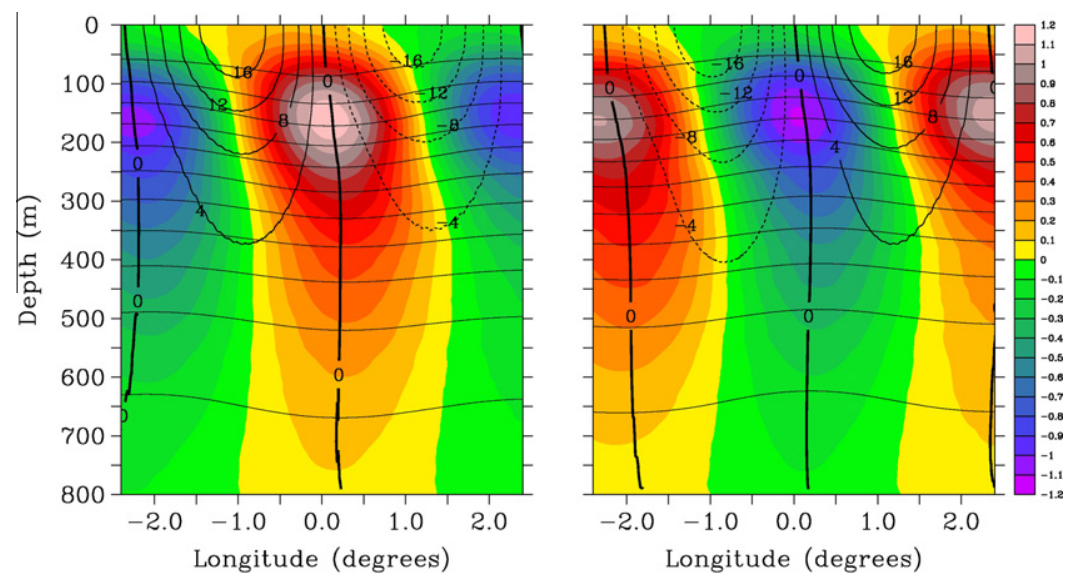

Fig. 6. Composite eddies showing the mean temperature (in colour) and velocities (contours) based on (left) 192 warm-core eddies and (right) 180 coldcore eddies (after Roemmich and Gilson, 2001 - copyright American Meteorological Society). (For interpretation of the references in colour in this figure legend, the reader is referred to the web version of this article.)

every part of the global ocean. These striations are oriented nearly zonally and in situ data comparisons show they are coherent vertically at least through $700 \mathrm{~m}$ depth. These alternating jets are also observed in annual mean model currents at $1000 \mathrm{~m}$ depth (Nakano and Hasumi, 2005).

Multi-mission altimetry has also been used to monitor the structure of polar jets and meanders in the Southern Ocean (Sokolov and Rintoul, 2007). The traditional view of the polar fronts, derived from hydrographic sections, is that the ACC is composed of three or four near continuous circumpolar fronts. However, maps of the gradient in sea level or SST reveal that the ACC consists of multiple frontal branches or filaments, as shown in Fig. 8. Sokolov and Rintoul (2007) used 12 years of weekly altimetry maps to show that the position of the maximum sea level gradient (i.e. a front) is strongly correlated with a particular value of absolute sea level. (Absolute sea level is obtained by adding the altimetric sea level anomalies to a mean surface dynamic height from climatology). The frontal positions inferred from the absolute sea level contours agree closely with the subsurface positions derived from hydrographic data. The reason is that although multiple branches of the fronts exist, and that they split and reform, strengthen and weaken, their mean position remains stable (see Fig. 8). This discovery has helped reconcile the differences between frontal locations from earlier studies.

Sallée et al. (2008) have used a similar technique to monitor the Subantarctic Front and the Polar Front around their circumpolar pathways. The fronts are strongly constrained by bathymetry, but in certain flat-bottom regions the fronts meander over large distances in response to the dominant climate mode forcing - either the Southern Annular Mode

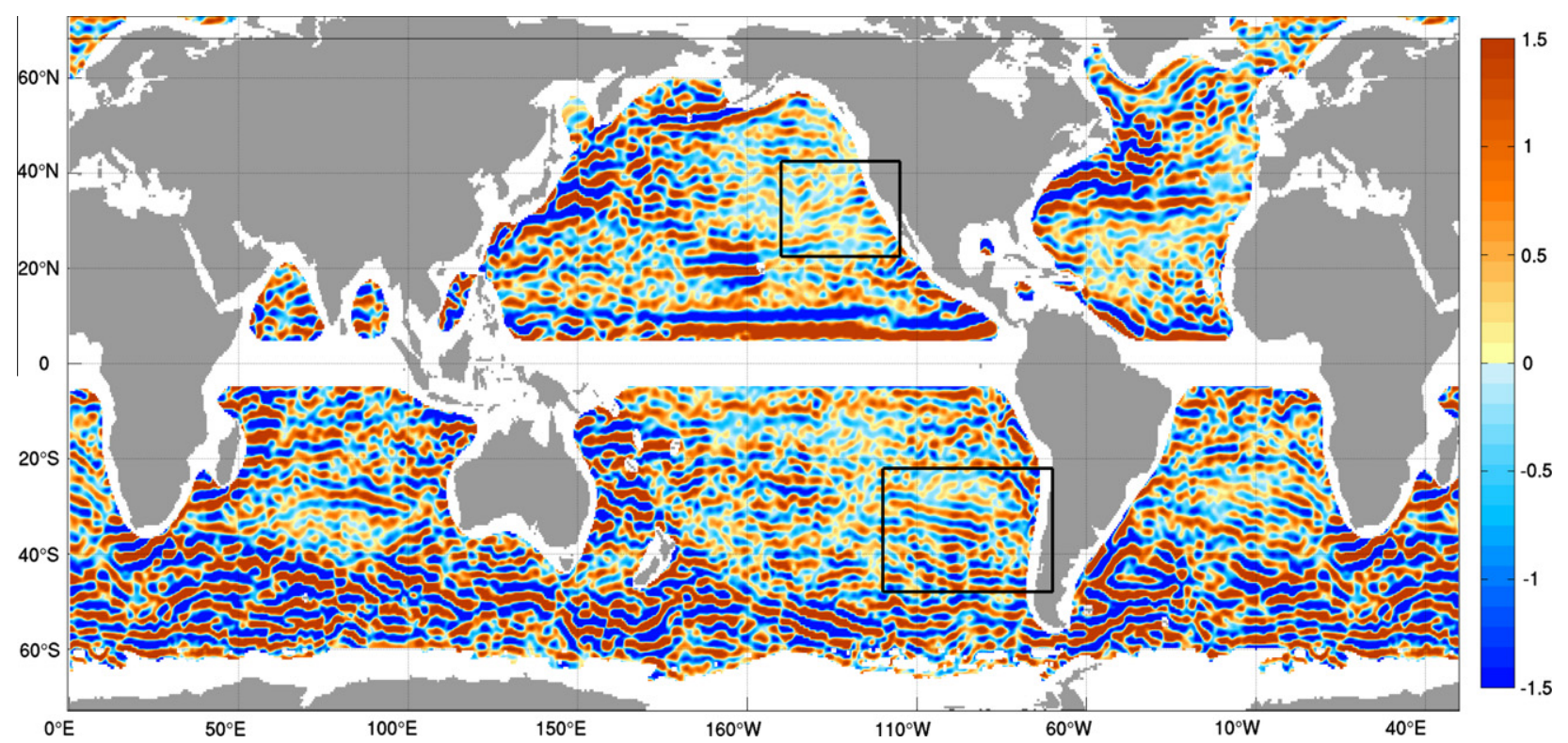

Fig. 7. 1993-2002 mean zonal surface geostrophic velocity calculated from a hybrid mean dynamic ocean topography product based on altimetry and surface drifters (Maximenko et al., 2008, (c) American Geophysical Union). 


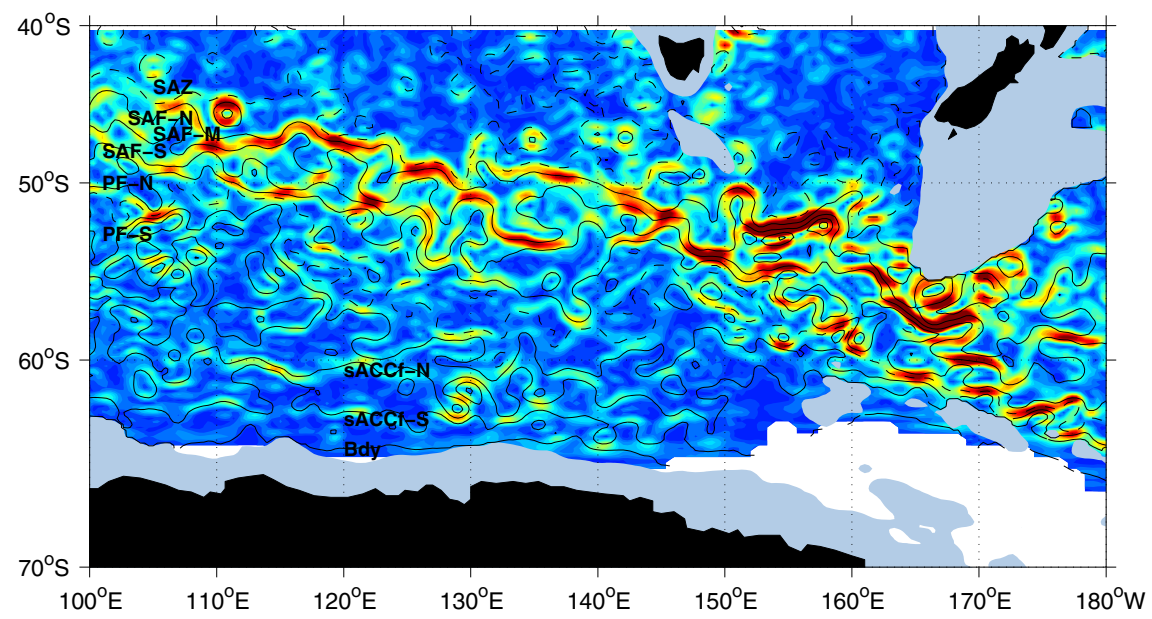

Fig. 8. Sea surface height gradient field (equivalent to geostrophic velocity in Fig. 7) in the Southern Ocean for one date (03/07/2002) overlaid with the absolute sea level contours corresponding to the 10 defined polar fronts. (after Sokolov and Rintoul, 2007, ( ) American Meteorological Society).

(SAM) or the El Nino Southern Oscillation (ENSO). Although the climate mode forcing is large-scale, and strongly zonal in the case of SAM, the ocean frontal response is shown to vary regionally. The regional response depends on the relative importance of the SAM versus ENSO forcing, bathymetric constraints and the mean latitude of the fronts. With altimetry, we can now monitor these frontal meanders and understand their response in relation to the different climate mode forcing. Knowing their position and their SST gradients is also important since they have an impact back on the atmospheric circulation.

\section{Atmospheric Interactions}

We know that mesoscale instabilities can be generated by wind anomalies. More recently, different studies have looked at how mesoscale features can impact back onto the atmospheric circulation.

Different authors have investigated the relationship between mesoscale sea level from merged altimetric data sets, satellite sea surface temperature (SST) and highresolution wind stress curl derived from the QuickScat scatterometer (e.g. White and Annis, 2003; O'Neill et al., 2005; Chelton and Xie, 2010). At the latitudes of the strong westerly winds (i.e. in all the western boundary currents and in the ACC), the SST signals associated with mesoscale eddies can alter the stability of the atmospheric boundary layer above the mesoscale feature. This creates surface zonal wind stress anomalies and also wind stress curl anomalies at the eddy scale (Fig. 9). Satellite observations have shown that warm (cold) SST perturbations produce positive (negative) wind stress magnitude perturbations, leading to short-scale perturbations in the wind stress curl and divergence fields that are linearly related to the crosswind and downwind components of the SST gradient, respectively (O'Neill et al., 2005). For a warm-core eddy, these wind stress curl anomalies (positive on the poleward side, negative on the equatorward side) are capable of shift-

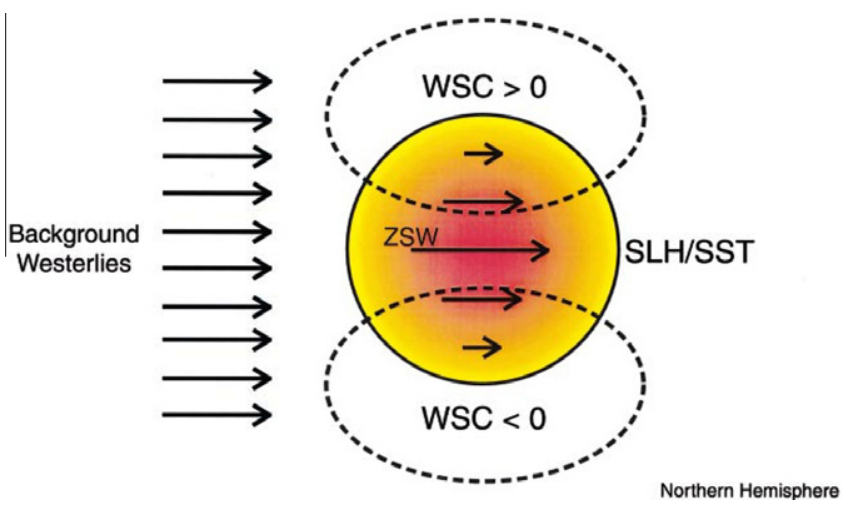

Fig. 9. Schematic diagramme of an anticyclonic (warm) mesoscale eddy in a background westerly wind field, which locally increases the zonal surface winds (ZSW) and induces cyclonic/anticyclonic wind stress curl (WSC) anomalies north/south of the eddy (after White and Annis, 2003, (C) American Meteorological Society).

ing the eddy equatorward and thus modifying the eddy dynamics. This equatorward tendency of warm-core eddies is consistent with altimetric observations of their propagation. The alternative patterns of mesoscale wind speed anomalies also introduce Ekman vertical velocity anomalies in the open ocean implying that important feedback effects can occur in upper ocean processes near SST fronts (O’Neill et al., 2003).

In the northeast Atlantic Ocean, the POMME experiment used a combination of altimetry, high-resolution SST products, in situ data and numerical models to study the impact of mesoscale eddies on the subduction of mode waters. As part of this experiment, a fine-resolution air-sea flux product was calculated over the domain (Caniaux et al., 2005), which clearly shows the imprint of the mesoscale ocean circulation on the overlying atmospheric fluxes. The strong mesoscale signal in the net heat flux comes mainly from the latent and sensible heat fluxes, driven by the difference in temperature between the ocean and the overlying atmosphere. The adjusted fluxes also show a mesoscale ocean imprint in the surface wind field. This 
mesoscale signal is absent from the standard lower resolution meteorological products (such as ECMWF or NCEP) used in most oceanographic studies. The relation between the mesoscale atmospheric forcing and the mesoscale ocean response is a new research domain which warrants more investigation in the future.

Another interesting application is how near-real time satellite altimetry and SST data are being used to improve hurricane and cyclone predictions. Hurricanes and cyclones will increase their intensity as they pass over regions of high SST, and that high SST will be maintained, despite the strong wind mixing, if the underlying heat content is large. In the Gulf of Mexico, the Loop Current regularly pinches off a warm, anticyclonic ring, which is associated with high sea level and SST, deepening isotherms in towards the centre and large heat content values. The NOAA/AOML group uses a simple 2-layer model with altimetry and SST observations to determine the Tropical Cyclone Heat Potential (TCHP) in the tropical Atlantic and the Gulf of Mexico. Fig. 10 shows that during Hurricane Katrina, the surface SST was greater than $28^{\circ} \mathrm{C}$ everywhere in the Gulf of Mexico (upper panel), but Hurricane Katrina showed a sharp increase in intensity and a change in direction as it passed over the warm ring pinched off the Loop Current (lower panel, Goni et al., 2009). Unfortunately for the residents of New Orleans, the warm ring was located close to the coast, and the Hurricane maintained its strong intensity till it struck land.
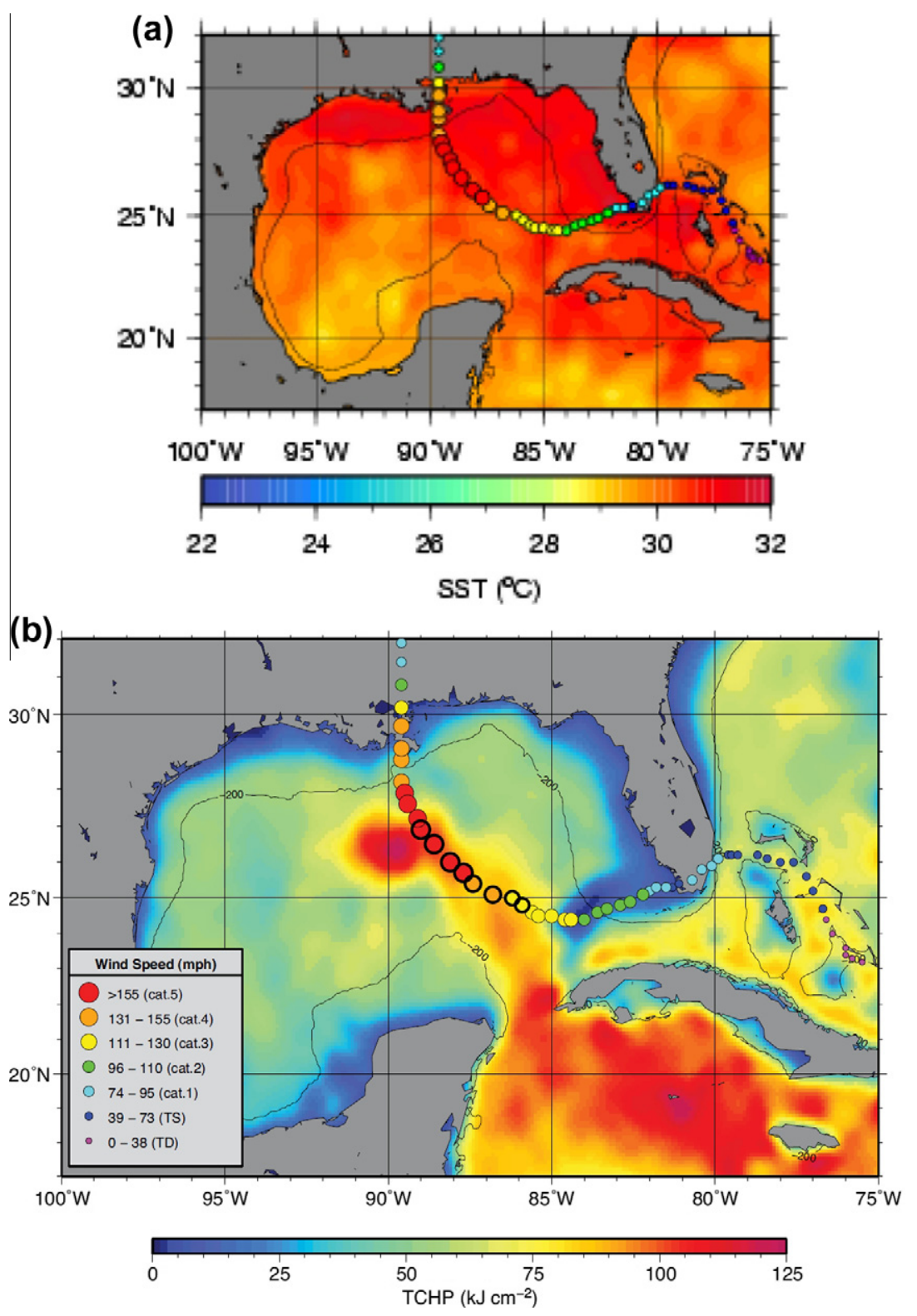

Fig. 10. (a) Satellite SST and (b) altimeter-derived estimates of Tropical Cyclone Heat Potential in the Gulf of Mexico on August 28, 2005. The circles in different colours indicate the track and intensity of Hurricane Katrina. (courtesy of NOAA/AOML, and after Goni et al., 2009, (C) The Oceanography Society, Inc.). 


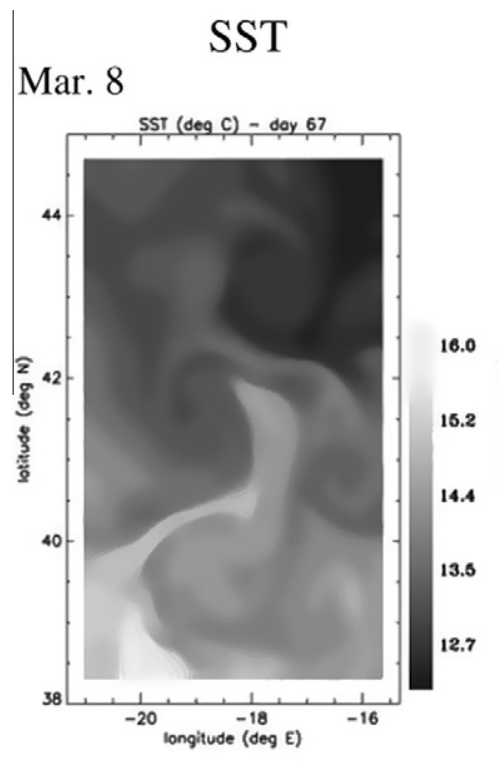

$\mathrm{W} \& \mathrm{U}, \mathrm{V}(50 \mathrm{~m})$

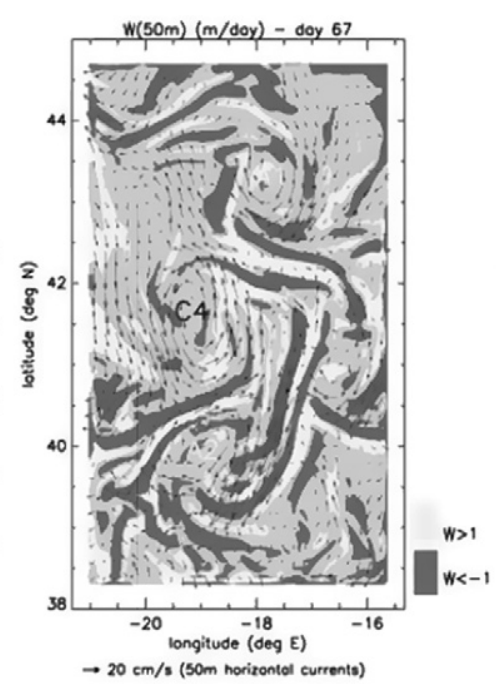

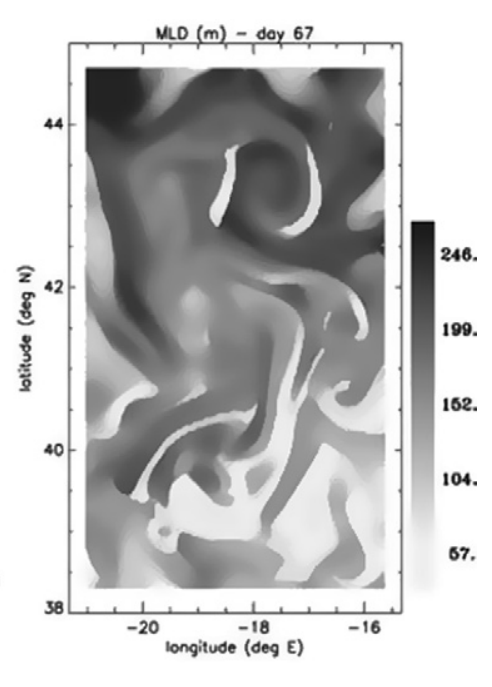

Fig. 11. Surface snapshots of (a) temperature, (b) the velocity field: vertical velocity is shaded, horizontal velocity vectors are overlaid, and (c) mixed layer depth, from a high-resolution numerical model of the POMME region in the NE Atlantic, forced by high-resolution atmospheric fields and constrained by altimetry and in situ observations. Note the sub-mesoscale filaments give rise to strong vertical velocities and large changes in the mixed layer depth (after Paci et al., 2005, (c) American Geophysical Union).

\section{Sub-mesoscale dynamics}

The present configuration of having two or more altimeters in complementary orbits has allowed an impressive progress in our understanding of ocean mesoscale dynamics. Although with four altimeters in flight we have a good constraint on the mesoscale field, we still cannot adequately sample the sub-mesoscale. As the name suggests, the sub-mesoscale concerns the small-scale features surrounding the mesoscale eddies, or around propagating planetary waves. These include the filament structures associated with the stirring at the periphery of mesoscale eddies, but also coastal squirts and jets, open-ocean fronts, small-scale equatorial waves, etc.

In order to study the sub-mesoscale, one solution currently in practice is to combine the high resolution satellite altimetry with very-high resolution SST products and/or regional numerical models (1-5 km resolution). The high-resolution models allow the sub-mesoscale features to develop, and the solution can be constrained towards the observed altimetric sea level and in situ observations. During the POMME experiment, Paci et al. (2005) have shown how the filaments around the mesoscale eddies play an active role in the mixed layer depth structure, and how intense vertical velocities occur in these filaments (Fig. 11). The vertical exchange in the filaments has consequences for the biogeochemical exchanges between the surface layers and at depth. It also has an impact on the subduction of mode waters, which do not occur along a theoretical north-south gradient as previously thought, but are subducted in the filament structures around the mesoscale eddies. The filaments greatly increase the depth range of these exchanges, and also increase the density of mode waters subducted.

Maps based on traditional nadir-looking altimetric configurations have allowed us to monitor and understand the larger oceanic mesoscale signals. However, we cannot observe the smaller mesoscale and sub-mesoscale signal between the tracks, and the background noise of the present generation of altimeters also masks the smaller scale signals in the alongtrack data. In the future, the technology proposed by the wide-swath SWOT interferometric altimeter aims at improving the smaller spacetime scales associated with mesoscale eddies and coastal zone dynamics (Fu and Ferrari, 2008). For SWOT, two synthetic-aperture radar (SAR) antennae measure simultaneously the radar signals reflected by the rough sea surface. The phase differences between the two signals and the range measurement allow interferometric calculation of the sea surface height. The intrinsic resolution of SAR is on the order of a few meters, allowing high spatial resolution of the measurement over two swaths of $60 \mathrm{~km}$ width. After smoothing, the random measurement noise can be reduced over the oceans to a level of $1 \mathrm{~cm}$ over $1 \times 1 \mathrm{~km}$ resolution cells. When these missions are finally flown, we expect to have a much better understanding of the important interactions between the mesoscale and sub-mesoscale dynamics.

\section{Summary and perspectives}

This brief review has highlighted how much progress has been made in the last decade in our understanding of ocean mesoscale dynamics, but has also outlined certain new 
observations of mesoscale and sub-mesoscale features which need to be further explored.

In terms of scientific questions, the coupling between mesoscale eddies and the atmospheric boundary layer has been revealed, and the question of the role of the mesoscale in climate is starting to be addressed. Combining highresolution altimetry with other satellite or in situ data provides complementary information for monitoring and understanding upper ocean processes. In situ data, such as tide gauges, gliders, Argo floats and surface drifters can be used in the data processing stages, to identify inaccuracies in the altimetry data, or to validate different processing techniques. Altimetry and tide gauges can be combined to give better sea level coverage in coastal regions (e.g. Saraceno et al., 2008). Combining altimetry and ocean colour data gives us enormous insight into the biological coupling associated with mesoscale eddies and fronts. Argo floats have revolutionized our vision of the time-variable vertical structure of the ocean, especially in the hardto-reach regions of the Southern Hemisphere and the centre of ocean gyres. The 10-day sampling of the Argo profiling floats make them the ideal partner for altimetry, to study the 3-D evolution of the mesoscale field (e.g. Guinehut et al., 2004). Data-based calculations of the eddy heat transport have been successfully made in different ocean basins, relying on the excellent space-time coverage of altimetry and SST, with in situ data providing the vertical projection. Equivalent calculations for the salt transport are lacking due to the lack of high resolution surface salinity data. The future satellite missions of SMOS and Aquarius, linked with Argo measurements, will greatly improve our monitoring of the large-scale salinity changes, but new techniques will need to be developed to access the mesoscale.

Since altimetric sea level rises and falls in response to surface and deep changes in the ocean, it provides the strongest constraint for the 4D mesoscale ocean circulation estimation through data assimilation. Its unique monitoring capabilities are of utmost importance for the development of operational oceanography services (e.g. safe and efficient off-shore activities, pollution monitoring, environmental management, security and sustainable use of marine resources) and for ocean, ecosystem and climate research (e.g. GODAE, 2000). However, a number of altimetry issues still need to be improved to correctly observe the full spectra of mesoscale processes. Coastal mesoscale data needs to be improved to have better coverage and more accurate data available. Accurate mean dynamic topographies and bathymetry are also required for a better representation of eddy-mean interactions, and the role of bathymetric gradients in generating mesoscale instabilities. We are also missing accurate global observations of the smaller mesoscale signals, from 10 to $200 \mathrm{~km}$, which are not well represented with the present altimetric coverage. Wide swath altimetry (e.g. SWOT) is also a very attractive possibility (Fu and Rodriguez, 2004) with the potential to sample the full spectra of mesoscale variability with a resolution better than 4-5 coordinated conventional altimeters.
The critical issue is now to ensure a long-term commitment for an operational high resolution altimeter system which is needed both for research and operational applications, especially in the coastal domain (e.g. marine security and pollution monitoring that require high resolution surface currents). The minimum requirement to continue the high-precision Jason series, and the complementary ERS/ENVISAT series, is planned and will include the future Jason-3 and Jason-CS missions from CNES/NASA/Eumetsat/NOAA and the ESA Sentinel series. The Ocean Surface Topography constellation project (Escudier and Fellous, 2009) recommends a high resolution altimeter system consisting of a constellation of three optimized altimeters in addition to the Jason series. The future of global mesoscale sea level observations will be centred around the optimal combination of future nadir altimetry, SAR altimetry and SAR interferometry missions.

\section{Acknowledgments}

The authors would like to acknowledge the outstanding work by the Ocean Surface Topography Science team, which brings together both scientific and technical teams, working to improve altimetric data and products. Much of the data analysed by the different authors was made available by CNES/AVISO, and via the DUACS project. $\mathrm{RM}$ and the $\mathrm{CTOH}$ receive finance from INSU, the Université Toulouse III, and the CNES TOSCA program.

\section{References}

Brachet, S., Le Traon, P.Y., Le Provost, C. Mesoscale variability from a high-resolution model and from altimeter data in the North Atlantic Ocean. J. Geophys. Res. 109, C12025, doi:10.1029/2004JC002360, 2004.

Boebel, O., Lutjeharms, J., Schmid, C., Zenk, W., Rossby, T., Barron, C. The Cape Cauldron: a regime of turbulent inter-ocean exchange. Deep Sea Res. 50, 57-86, II, 2003.

Caballero, A., Pascual, A., Dibarboure, G., Espino, M. Sea level and eddy kinetic energy variability in the Bay of Biscay inferred from satellite altimeter data. J. Mar. Sys. 72, 116-134, 2007.

Caniaux, G., Belamari, S., Giordani, H., Paci, A., Prieur, L., Reverdin, G. A 1 year sea surface heat budget in the northeastern Atlantic basin during the POMME experiment: 2. Flux optimization. J. Geophys. Res. 110, doi:10.1029/2004JC002695, 2005.

Carrere, L., Lyard, F. Modeling the barotropic response of the global ocean to atmospheric wind and pressure forcing - comparisons with observations. Geophys. Res. Lett. 30 (6), 1275-1278, ISSN: 0094-8276, 2003.

Carton, J.A., Chao, Y. Carribean Sea eddies inferred from Topex/ Poseidon altimetry and 1/6 Atlantic Ocean model simulation. J. Geophys. Res. 104 (C4), 7743-7752, 1999.

Chaigneau, A., Morrow, R., Rintoul, S. Seasonal and interannual evolution of the mixed layer in the Antarctic Zone, south of Tasmania. Deep-Sea Res. 1 (51), 2047-2072, 2004.

Chaigneau, A., Pizarro, O. Eddy characteristics in the eastern South Pacific. J. Geophys. Res. 110, doi:10.1029/2004JC002815, 2005.

Chelton, D.B., Schlax, M.G. Global observations of oceanic Rossby waves. Science 272, 234-238, 1996. 
Chelton, D.B., Schlax, M.G., Samelson, R.M., de Szoeke, R.A. Global observations of large oceanic eddies. Geophys. Res. Lett. 34, L15606, doi:10.1029/2007GL030812, 2007.

Chelton, D.B., Xie, S.-P. Coupled ocean-atmosphere interaction at oceanic mesoscales. Oceanography 23 (4), 52-69, 2010.

Chelton, D.B., Schlax, M.G., Samelson, R.M. Global observations of nonlinear mesoscale eddies. Prog. Oceanogr. 91, 167-216, 2011.

Cushman-Roisin, B., Chassignet, E.P., Tang, B. Westward motion of mesoscale eddies. J. Phys. Oceanogr. 20, 97-113, 1990.

de Ruitjer, W.P.M., van Aken, H.M., Beier, E.J., Lutjeharms, J.R.E., Matano, R.P., Schouten, M.W. Eddies and dipoles around South Madagascar: formation, pathways and large-scale impact. Deep-Sea Res. 1 (51), 383-400, 2004.

de Ruitjer, W.P.M., Biastoch, A., Drijfhout, S.S., Lutjeharms, J.R.E., Matano, R.P., Pichevin, T., van Leeuwen, P.J., Weijer, W. IndianAtlantic inter-ocean exchange: dynamics, estimation and impact. J. Geophys. Res. 104 (20), 20885-20910, 1999.

Dibarboure, G., Pujol, M.-I., Briol, F., Le Traon, P.-Y., Larnicol, G., Picot, N., Mertz, F., Ablain, M. Jason-2 in DUACS: updated system description, first tandem results and impact on processing and products. Marine Geod. 34, 214-241, 2011.

Dussurget, R., Birol, F., Morrow, R., Demey, P. Fine resolution altimetry data for a regional application in the Bay of Biscay. Marine Geod. 34, 447-476, 2011.

Eden, C., Böning, C. Sources of eddy kinetic energy in the Labrador Sea. J. Phys. Oceanogr. 32, 3346-3363, 2002.

Escudier, P., Fellous, J.L. Ocean Surface Topography Constellation User Requirements Document. http://www.ceos.org/images/OST/SatelliteAltimetryReport_2009-2010.pdf, 2009.

Fang, F., Morrow, R. Warm-core eddy propagation in the southeast Indian Ocean. Deep Sea Res. 2 (50), 2245-2261, 2003.

Frankignoul, C., Müller, P. Quasi-geostrophic response of an infinite betaplane ocean to stochastic forcing by the atmosphere. J. Phys. Oceanogr. 9, 104-127, 1979.

Fu, L.-L. Pattern and velocity of propagation of the global ocean eddy variability. J. Geophys. Res. 114, C11017, doi:10.1029/2009JC005349, 2009.

Fu, L.-L., Chelton, D.B. Large-scale ocean circulation, in: Fu, L.-L., Cazenave, A. (Eds.), Satellite Altimetry and Earth Sciences. A Handbook of Techniques and Applications, Academic Press, pp. 133-169, 2001.

Fu, L-L., Ferrari, R. Observing oceanic submesoscale processes from space. Eos, Trans., Am. Geophys. Union 89 (48), 488, 2008.

Fu, L.-L., Rodriguez, R. High-resolution measurement of ocean surface topography by radar interferometry for oceanographic and geophysical applications, in: Sparks, R.S.J., Hawkesworth, C.J. (Eds.), AGU Geophysical Monograph 150, IUGG Vol. 19: State of the Planet: Frontiers and Challenges, pp. 209-224, 2004.

Fu, L.L., Chelton, D.B., Le Traon, P.-Y., Morrow, R. Eddy dynamics from satellite altimetry. Oceanogr. Mag. 23 (4), 2010.

Gille, S.T. Mean sea surface height of the Antarctic circumpolar current from GEOSAT data: methods and application. J. Geophys. Res. 99, 18255-18273, 1994.

GODAE Strategic Plan. Prepared by the International GODAE Steering Team, GODAE Report No. 6, December, 2000.

Goni, G.J., DeMaria, M., Knaff, J., Sampson, C., Ginis, I., Bringas, F., Mavume, A., Lauer, C., Lin, I.-I., Ali, M.M., Sandery, Paul, RamosBuarque, S., Kang, K., Mehra, A., Chassignet, E., Halliwell, G. Applications of satellite-derived ocean measurements to tropical cyclone intensity forecasting. Oceanography 22 (3), 176-183, 2009.

Greenslade, D.J.M., Chelton, D.B., Schlax, M.G. The Midlatitude resolution capability of sea level fields constructed from single and multiple satellite altimeter datasets. J. Atmos. Ocean. Tech. 14, 849870, 1997.

Guinehut, S., Le Traon, P.Y., Larnicol, G., Philipps, S. Combining Argo and remote-sensing data to estimate the ocean three-dimensional temperature fields - a first approach based on simulated observations.
J. Mar. Systems 46 (1-4), 85-98, doi:10.1016/j.jmarsys.2003.11.022, 2004.

Hátún, H., Eriksen, C.C., Rhines, P.B. Buoyant eddies entering the Labrador Sea observed with gliders and altimetry. J. Phys. Oceanogr. 37 (12), 2838-2854, 2007.

Hogg, A.M., Blundell, J.R. Interdecadal variability of the Southern Ocean. J. Phys. Oceanogr. 36, 1626-1644, 2006.

Hughes, C.W., Jones, M.S., Carnochan, S. Use of transient features to identify eastward currents in the Southern Ocean. J. Geophys. Res. 103 (C2), 2929-2943, 1998.

Isern-Fontanet, J., Garcia-Ladona, E., Font, J. Identification of marine eddies from altimeter maps. J. Atmos. Ocean. Tech. 20, 772-778, 2003.

Isoguchi, O., Kawamura, H. Eddies advected by time-dependent Sverdrup circulation in the western boundary of the subarctic North Pacific. Geophys. Res. Lett. 30 (15), 1794, doi:10.1029/2003GL017652, 2003.

Jayne, S.R., Marotzke, J. The oceanic eddy heat transport. J. Phys. Oceanogr. 32, 3328-3345, 2002.

KKarsten, R.H., Marshall, J. Constructing the residual circulation of the ACC from observations. J. Phys. Oceanogr. 32, 3315-3327, 2002.

Kelly, K.A., Gille, S.T. Gulf stream surface transport and statistics at $69^{\circ}$ W from the GEOSAT altimeter. J. Geophys. Res. 95, 3149-3161, 1990.

Koblinsky, C.J., Gaspar, P., Lagerloef, G. The Future of Spaceborne Altimetry: Oceans and Climate Change. Joint Oceanographic Institutions Incorporated, Washington, DC, pp. 75, 1992.

Le Traon, P.Y. Time scales of mesoscale variability and their relationship with space scales in the North Atlantic. J. Mar. Res. 49, 467-492, 1991.

Le Traon, P.Y., Dibarboure, G. Velocity mapping capabilities of present and future altimeter missions: the role of high frequency signals. J. Atmos. Ocean Tech. 19, 2077-2088, 2002.

Le Traon, P.Y., Dibarboure, G. Illustration of the contribution of the tandem mission to mesoscale studies. Marine Geod. 27, 3-13, 2004.

Le Traon, P.-Y., Morrow, R.A. Ocean currents and mesoscale eddies, in: Fu, L.-L. Cazenave, A. (Eds.), Satellite Altimetry and Earth Sciences. A Handbook of Techniques and Applications, Academic Press, pp. 171-215, 2001.

Lilly, J.M., Rhines, P.B., Schott, F., Lavender, K., Lazier, J., Send, U., D'Asaro, E. Observations of the Labrador Sea eddy field. Prog. Oceanogr. 59 (1), 75-176, doi:10.1016/j.pocean.2003.08.013, 2003.

Lozier, M.S. Evidence of large-scale eddy-driven gyres in the North Atlantic. Science 277, 361-364, 1997.

Maximenko, N.A., Melnichenko, O.V., Niiler, P.P., Sasaki, H. Stationary mesoscale jet-like features in the ocean. Geophys. Res. Lett. 35, L08603, doi:10.1029/2008GL033267, 2008.

McWilliams, J.C. The emergence of isolated coherent vortices in turbulent flow. J. Fluid Mech. 146, 2143, 1984.

Meredith, M.P., Hogg, A.M. Circumpolar response of Southern Ocean eddy activity to changes in the Southern Annular Mode. Geophys. Res. Lett. 33, L16608, doi:10.1029/2006GL026499, 2006.

Morrow, R., Birol, F., Griffin, D., Sudre, J. Divergent pathways of anticyclonic and cyclonic eddies. Geophys. Res. Lett. 31, L24311, doi:10.1029/2004GL020974, 2004a.

Morrow, R.A., Brut, A., Chaigneau, A. Seasonal and interannual variations of the upper ocean energetics between Tasmania and Antarctica. Deep Sea Res. (50/3), 339-356, 2002.

Morrow, R.A., Coleman, R., Church, J.A., Chelton, D.B. Surface eddy momentum flux and velocity variances in the Southern Ocean from Geosat altimetry. J. Phys. Oceanogr. 24, 2050-2071, 1994.

Morrow, R., Donguy, J.R., Chaigneau, A., Rintoul, S. Cold core anomalies at the Subantarctic Front, south of Tasmania. Deep-Sea Res. 1 (51), 1417-1440, 2004 b.

Morrow, R.A., Fang, F., Fieux, M., Molcard, R. Anatomy of three warmcore Leeuwin Current eddies. Deep Sea Res. 2 (50), 2229-2243, 2003.

Morrow, R., Ward, M.L., Hogg, A.M., Pasquet, S. Eddy response to Southern Ocean climate modes. J. Geophys. Res. 115, C10030, doi:10.1029/2009JC005894, 2010. 
Nakano, H., Hasumi, H. A series of zonal jets embedded in the broad zonal flows in the Pacific obtained in eddy-permitting ocean general circulation models. J. Phys. Oceanogr. 35 (4), 474 488, 2005.

Niiler, P.P., Maximenko, N.A., Panteleev, G.G., Yamagata, T., Olson, D.B. Near-surface dynamical structure of the Kuroshio Extension. J. Geophys. Res. 108 (C6), 3193, doi:10.1029/2002JC001461, 2003.

O’Neill, Larry. W., Dudley, B. Chelton., Steven, K. Esbensen. Observations of SST-induced perturbations of the wind stress field over the Southern Ocean on seasonal timescales. J. Climate 16, 2340-2354, 2003.

O’Neill, Larry W., Chelton, Dudley B., Esbensen, Steven K., Wentz, Frank J. High-resolution satellite measurements of the atmospheric boundary layer response to SST variations along the Agulhas return current. J. Climate 18, 2706-2723, 2005.

Paci, A., Caniaux, G., Gavart, M., Giordani, H., Levy, M., Prieur, L., Reverdin, G. A high-resolution simulation of the ocean during the POMME experiment: simulation results and comparison with observations. J. Geophys. Res. 110, doi:10.1029/2004JC002712, 2005.

Pascual, A., Pujol, M.I., Larnicol, G., Le Traon, P.Y., Rio, M.H. Mesoscale mapping capabilities of multisatellite altimeter missions: first results with real data in the Mediterranean Sea. J. Mar. Systems 65 (2007), 190-211, doi:10.1016/j.jmarsys.2004.12.004, 2005.

Pascual, A., Faugere, Y., Larnicol, G., Le Traon, P.Y. Improved description of the ocean mesoscale variability by combining four satellite altimeters. Geophys. Res. Lett. 33 (2), 55-56, L02611, 2006.

Penduff, T., Barnier, B., Dewar, W.K., O'Brien, J.J. Dyn ami cal response of the oceanic eddy field to the North Atlantic oscillation: a modeldata comparison. J. Phys. Oceanogr. 34, 2615-2629, 2004.

Pujol, M.I., Larnicol, G. Mediterranean sea eddy kinetic energy variability from 11 years of altimetric data. J. Mar. Systems 58, 121-142, 2005.

Qiu, B. Recirculation and seasonal change of the Kuroshio from altimetry observations. J. Geophys. Res. 97, 17801-17813, 1992.

Qiu, B. Seasonal eddy modulation of the North Pacific subtropical countercurrent: Topex/Poseidon observations and theory. J. Phys. Oceanogr. 29, 2471-2486, 1999.

Qiu, B., Chen, S. Seasonal modulations in the eddy field of the South Pacific Ocean. J. Phys. Oceanogr. 34, 1515-1527, 2004.

Qiu, B., Chen, S. Eddy-induced heat transport in the subtropical North Pacific from Argo, TMI and altimetry measurements. J. Phys. Oceanogr. 35, 458-473, 2005.

Roblou, L., Lamouroux, J., Bouffard, J., Le Hénaff, M., Lombard, A., Marsaleix, P., De Mey, P. Post-processing altimeter data toward coastal applications and integration into coastal mode, in: Vignudelli, S., Kostianoy, A., Cipollini, P., Benveniste, J. (Eds.), Dans Coastal Altimetry. Springer-Verlag, 2010.
Roemmich, D., Gilson, J. Eddy transport of heat and thermocline waters in the North Pacific: a key to interannual/decadal climate variability? J. Phys. Oceanogr. 31, 675-688, 2001.

Sallée, J.B., Speer, K., Morrow, R. Southern Ocean fronts and their variability to climate modes. J. Climate 21 (12), 3020-3039, 2008.

Sallée, J.B., Wienders, N., Morrow, R., Speer, K. Formation of Subantarctic mode water in the Southeastern Indian Ocean. Ocean Dynam. 56, 525-542, 2006.

Sangrà, P., Pascual, A., Rodríguez-Santana, Á., Machín, F., Mason, E., McWilliams, J.C., Pelegrí, J.L., Dong, C., Rubio, A., Arístegui, J., Marrero-Díaz, Á., Hernández-Guerra, A., Martínez-Marrero, A., Auladell, M. The Canary eddy corridor: a major pathway for longlived eddies in the subtropical North Atlantic. Deep-sea Res. 56 (12), 2100-2114, doi:10.1016/j.dsr.2009.08.008, 2009.

Saraceno, M., Strub, P.T., Kosro, P.M. Estimates of sea surface height and near-surface alongshore coastal currents from combinations of altimeters and tide gauges. J. Geophys. Res. 113, C11013, doi:10.1029/ 2008JC004756, 2008.

Smith, R.D., Maltrud, M.E., Bryan, F.O., Hecht, M.W. Numerical simulation of the North Atlantic ocean at 1/10. J. Phys. Oceanogr. 30 (7), 1532-1561, 2000.

Sokolov, S., Rintoul, S.R. Multiple jets of the antarctic circumpolar current south of Australia. J. Phys. Oceanogr. 37, 1394-1412, 2007.

Souza, J.M.A.C., de Boyer Montegut, C., Le Traon, P.Y. Mesoscale eddies in the South Atlantic. Ocean Sci. Discuss. 8, 483-531, doi:10.5194/osd-8-483-2011, 2011.

Stammer, D. On eddy characteristics, eddy transports and mean flow properties. J. Phys. Oceanogr. 28, 727-739, 1998.

Stammer, D., Theiss, J. Velocity statistics inferred from the T/P-Jason tandem mission data. Marine Geod. 27, 551-575, 2004.

Stammer, D., Wunsch, C. Temporal changes in eddy energy of the oceans. Deep Sea Res. 46, 77-108, 1999.

Tai, C.K., White, W.B. Eddy variability in the Kuroshio extension as revealed by GEOSAT altimetry: energy propagation away from the jet, Reynolds stress and seasonal cycle. J. Phys. Oceanogr. 20, 1761-1777, 1990.

Van Ballegooyen, R.C., Grundlingh, M.L., Lutjeharms, J.R.E. Eddy fluxes of heat and salt from the southwest Indian ocean into the southeast Atlantic ocean. J. Geophys. Res. 99, 14053-14070, 1994.

White, W.B., Annis, J.L. Coupling of extratropical mesoscale eddies in the ocean to westerly winds in the atmospheric boundary layer. J. Phys. Oceanogr. 33, 1095-1107, 2003. 